\title{
Assessing Current And Preferred Sources Of Information On Adolescents' Sexual And Reproductive Health In Southeast Nigeria: Improving Adolescent Health Programming
}

Chibuike Innocent Agu ( $\nabla$ aguchibuike14@yahoo.com )

Alex Ekwueme Federal University, Abakaliki https://orcid.org/0000-0002-9248-7877

Chinyere Ojiugo Mbachu

Department of Community Medicine, University of Nigeria,Nsukka

Ifunanya Clara Agu

Health Policy Research Group, University of Nigeria, Enugu Campus

Chinyere Okeke

Department of Community Medicine, University of Nigeria, Enugu Campus

Uchenna Ezenwaka

Department of Health Administration and Management, University of Nigeria, Enugu Campus, Enugu

Mildred Ndubuisi

Health Policy Research Group, University of Nigeria, Enugu Campus, Enugu

Nkoli Ezumah

Health Policy Research Group, University of Nigeria, Enugu Campus, Enugu

Obinna Onwujekwe

Department of Health Administration and Management, University of Nigeria, Enugu Campus, Enugu

Research article

Keywords: Sexual health, Reproductive health, Adolescent, Information, SRH, Nigeria

Posted Date: July 27th, 2020

DOI: https://doi.org/10.21203/rs.3.rs-42179/v1

License: (c) (i) This work is licensed under a Creative Commons Attribution 4.0 International License.

Read Full License 


\section{Abstract}

Background: Many adolescents lack appropriate information about their sexual and reproductive health $(\mathrm{SRH})$. Although there are numerous information on SRH, they vary in content and quality, and these have implications for the accuracy and appropriateness of SRH information adolescents can access. This study examined the sources of SRH information for adolescents, the value adolescents place on these sources and their significance for adolescent health programming.

Method: This was a mixed methods, community-based, cross-sectional study that was conducted in six local government areas in Ebonyi state, Nigeria. Quantitative data were collected using pre-tested questionnaire that was administered to 1057 unmarried adolescents aged 13-18 years. The qualitative data were: Seventy-seven in-depth interviews (IDIs) with stakeholders; twelve (12) focus group discussions (FGDs) with adolescents; and six FGDs with village head. Descriptive and inferential analyses were performed for quantitative data using Stata software while thematic framework approach was used to analyze qualitative data.

Result: It was found that $60.5 \%$ and $39.8 \%$ of adolescents reported that school teachers and mothers respectively were their major sources of information about pubertal changes, while teachers $(36.3 \%)$ and friends $(29.8 \%)$ were the commonest sources of information on relationship with opposite sex. There were statistically significant associations between sources of information about relationships and age category $(\mathrm{p} \leq 0.09)$. Additional common sources of SRH information elicited through IDIs with adolescents include internet, social media and mass media. Although adolescents valued the information provided by teachers and parents, they preferred information on SRH from their friends/peers, social media and mass media because these sources are easy to access with a guarantee of some level of confidentiality. In the opinion of parents and other stakeholders, sources of appropriate SRH information for adolescents were health workers, teachers, parents and adult family members; whereas peers/friends and social media were considered as inappropriate sources of SRH information for adolescents.

Conclusion: Efforts at addressing the need of adolescents for SRH information should be targeted at their valued and preferred sources, whilst maintaining a delicate balance with the choices and expectations of their parents and adult family members.

\section{Background}

Globally, the number of adolescents today is at an all-time high of about 1.2 billion people, which is approximately $16 \%$ of the world's population [1,2]. Up to $70 \%$ of this number live in developing nations [3]. In sub-Saharan Africa (SSA), adolescents aged 10-19 years, make up a great proportion of the population, accounting for 23 per cent of the region's population [1].

Adolescence is a period of development characterized by increased sexual ideation and urge, development of sexual values, and initiation of sexual activity $[4,5]$. This period is a time of sexual risk taking and experimentation with often, dire consequences. At this stage, lack of sexual and reproductive 
health information and services further exposes them to high risk sexual behaviours, resulting to unwanted pregnancy, unsafe abortion, and Sexually Transmitted Infections [STI] including HIV/AIDS [6]. Indeed, many adolescents lack adequate and appropriate information about sexual health and relationships, making them vulnerable to sexual exploitation $[7,8]$.

Access to information, education and services have been highlighted as keys to promotion of sexual and reproductive health and rights (SRHR) for young people including adolescents [9]. This led to the recommendation at the International Conference on Population and Development [ICPD] held in Cairo in 1994, that adolescents should be provided with appropriate information and services needed to improve their sexual and reproductive health [10]. Nigeria adopted the regional reproductive health strategy and endorsed all the components of SRH as entrenched in the ICPD platform for action except "the provision of safe abortion services," which is contrary to the law in Nigeria [11].

However, in Nigeria, sexuality education remains low, with poor access to appropriate SRH information due to cultural restrictions in the country, leaving adolescents with poor sexual and reproductive health choices $[3,12]$. For instance, first sexual exposures have been reported to mostly occur in the backgrounds of poor and inaccurate knowledge of sexual and reproductive health $[13,14]$. There are also, wrong perceptions, inappropriate SRH information and poor knowledge about contraceptives and safe sex among adolescents in Nigeria, which results to unprotected sexual practices among the age group $[15,16]$.

In Nigeria as in some other Sub-Saharan Africa countries, parents are often preferred as the main source of SRH information for adolescents, but parents and other adults do not feel comfortable discussing SRH issues, especially sex-related matters with young people $[14,17]$. Moreover, a good number of adolescents pass through school, and hence the school setting has been projected as a cost-effective source of SRH information to adolescents but, many teachers often have reservations about giving such information to adolescents [18]. Besides, comprehensive sexual and reproductive health education is poorly implemented in Nigerian schools as a result of similar social and cultural barriers that inhibit open discussions about sexual matters between young people and adults $[17,19]$.

Nigeria has a very young population with over 30 million adolescents in the same age bracket [20]. In the light of their proportion, energy and resourcefulness, young people's health especially their sexual and reproductive health, has great implications for the overall national development of a country [9]. Thus, they need access to SRH information in order to reduce risky sexual behaviours and the resultant poor outcomes among them. A key concern is how adolescents in the state currently receive SRH information and their preferred means of communication in future. Identifying the sources of SRH information and adolescents' preferences provides useful information for the design of future interventions. This will provide hints for cost-effective strategies for information and promotion of the health of adolescents [21, 22]. Equally important are the perceptions of other stakeholders, such as, parents, health workers, policy makers, religious and community leaders on where and how adolescents access SRH information, and the values adolescents place on the information received from these sources. 
Unfortunately, there has been paucity of studies on this aspect of adolescent sexual and reproductive health especially in the study state where about $9.6 \%$ of adolescent girls aged 15 to 19 years have begun child bearing due to lack of appropriate SRH information [23]. This paper therefore, contributes knowledge of the preferred sources of SRH information by adolescents and the value adolescents place on these sources of information. It also explored the perception of adolescents and other stakeholders on adequacy and appropriateness of the various sources. Knowledge of these will be useful for selecting strategies for delivering accurate and appropriate SRH information to adolescents.

\section{Methods}

\section{Study design and study area}

This was a cross-sectional study that used mixed method approach to collect quantitative and qualitative data. This study was undertaken in Ebonyi State, southeast geopolitical zone of Nigeria. The state has three senatorial zones with thirteen local government areas. It has $5,533 \mathrm{~km}^{2}$ estimated land area and more than $40 \%$ of its total population are below 15 years of age [17]. The state has an estimated annual growth rate of $2.7 \%$ and its adolescents' population is projected to double by year 2050 [17]. It has been reported that the state has high maternal mortality rate (602 per 100,000 population), and $39.7 \%$ of these mortalities occur among adolescent girls age 15-19 years [24-26].

\section{Study population}

The study population for quantitative survey were male and female in-school and out-of-school unmarried adolescents aged 13 to 18 years living in the selected households with a parent/caregiver whose parents/caregivers gave consent. Adolescents who were household guests or mentally challenged were excluded from the survey.

The study population for in-depth interview consisted of policy makers, program managers and implementing partners in adolescent health at the State level. Participants were recruited from various government and non-governmental organizations such as; State ministry of health, State ministry of youth and sports development, State ministry of education, State ministry of women affairs and social development, State house of assembly, State universal basic education board, State primary health care development agency, and civil society organisations. Other participants were adolescents aged 13 to 18 years, community leaders, religious leaders and community influencers such as town union chairmen, ward development chairmen, health service providers (formal and informal), secondary school principals and parents/caregivers of adolescents aged 13 to 18 years.

\section{Sampling technique}

A modified cluster sampling technique was used. Six local government areas (LGAs) were purposively selected so as to ensure representation of geopolitical and geographical locations in terms of place of residence (Urban/Rural). One cluster (defined as an autonomous community with a traditional ruler) was 
selected from each LGA. Within each cluster, the nearest public facility from the main entrance was identified as the starting point from which households were consecutively selected. All eligible adolescents in selected households were invited to participate in the survey.

The interview participants were purposively selected from the six communities and State level. The selection was due to their current participation in adolescent sexual and reproductive health needs and also to represent a wide range of values, culture and religious perception of adolescents' access to appropriate $\mathrm{SRH}$ information.

For the quantitative study, the sample size for survey was determined from Glenn's table of sample sizes that would be necessary for given combinations of precision, confidence level and variability for different population sizes [27]. To achieve a $5 \%$ precision at $95 \%$ confidence interval for population $>100,000$ a minimum sample size of 400 was determined. However, this sample size was doubled and further increased to 1,100 to enable the analysis of sub-group data and also to account for incomplete responses. A range of interview participants were identified and interviewed until saturation point was attained.

\section{Data Collection}

The quantitative data was collected using a structured questionnaire that was adapted from the World Health Organisation's (WHO) illustrative questionnaire for interview-surveys with young people [28] (see supplementary file 1). The questionnaire was used to collect data on adolescents' source of information on puberty and relationship with the opposite sex, among other SRH variables. The data was collected by fifty-four research assistants who were trained for a period of ten days. Electronic and paper copies of the questionnaires were used to collect data concurrently and the electronic copies were uploaded to android tablets using surveyCTO.

The survey and interview guides were pretested in a contiguous site among target population group. Indepth interview (IDI) and focus group discussion (FGD) guides were used for qualitative data collection. The interview guides were developed by a team of qualitative research experts.

Seventy-seven (77) IDI, six (6) FGDs with village heads and twelve (12) FGDs with adolescents were conducted using pretested semi structured interview guides. Information was collected on sources of information on pubertal changes, relationships, sex, pregnancy and its prevention, preferred sources and reasons for that. In addition, the perceptions of the other stakeholders on the adequacy and appropriateness of information provided by the different sources as well as the most important source to adolescents were elicited.

Interviews were conducted by trained and experienced qualitative researchers. All interviews were audio recorded and lasted between 50 to 70 minutes. The FGDs ranged from 8 to 13 participants Qualitative data collection was conducted over a period of one month. The various community interviews consisted 
of three facilitators: one moderator, one note taker and a local translator/guide. The discussions were held in venues that were convenient for participants while ensuring confidentiality.

\section{Data management and analysis}

For the quantitative data, one hundred and forty-five (1045) questionnaires were found to be completely filled after cleaning of data, giving a $95 \%$ response rate. The independent variables include age, place of residency (urban/rural), gender and schooling status, while the dependent variables are the sources of $\mathrm{SRH}$ information on signs of puberty and on relationship with opposite sex. Descriptive analysis was performed and proportions were reported for categorical variables. Proportions based on a denominator of less than 25 participants were not reported.

For the qualitative data, the audio files were transcribed verbatim in the language of the interview and then translated to English. Transcripts were processed and edited with Microsoft word. Each transcript was anonymized using unique codes that were developed by the research team. Prior to analysis, all transcripts were read by two independent researchers in other to gain full insight of the data. Then the richest FGD and IDI transcripts were selected for comprehensive study and coding.

The data were analyzed using a thematic framework approach. The key themes relating to sources of sexual and reproductive health information among adolescents were generated. They include sources of $\mathrm{SRH}$ information, perceived value, adequacy and appropriateness of sources of SRH information. This formed the initial coding framework which was tested on two other new transcripts (one of FGD and IDI). It was later refined and the final coding framework was developed, then applied to all the transcripts.

\section{Results}

Table 1 shows the demographic characteristics of survey respondents. Approximately $51 \%$ of adolescents in the survey were residing in urban areas, whereas $49 \%$ of them lived in rural areas. There were $598(57.2 \%)$ girls and $447(42.8 \%)$ boys in the survey. Majority $(92.4 \%)$ of the surveyed respondents were in-school while only $7.6 \%$ were out of school adolescents. 
Table 1

Socio-demographic characteristics of survey respondents

\begin{tabular}{|lll|}
\hline Variables ( $=$ 1045) & Frequency $(\mathbf{n})$ & Percent (\%) \\
\hline Age in single years & & \\
\hline 13 & 180 & 17.4 \\
14 & 219 & 20.9 \\
\hline 15 & 162 & 15.5 \\
\hline 16 & 151 & 14.5 \\
\hline 17 & 136 & 12.9 \\
\hline 18 & 197 & 18.8 \\
\hline Gender & & \\
\hline Female & 598 & 57.2 \\
\hline Male & 447 & 42.8 \\
\hline Place of residence & & \\
\hline Urban & 551 & 50.7 \\
\hline Rural & 494 & 49.3 \\
\hline Schooling & & 92.4 \\
\hline In-school & 966 & \\
\hline Out-of-school & 79 & \\
\hline
\end{tabular}

Table 2 highlights the demographic distribution of in-depth interview respondents. There were 38 males and 39 females who were interviewed. Forty-nine of these respondents resides in urban areas while 28 respondents resides in rural areas. 
Table 2

Socio-demographic distribution of IDI respondents

\begin{tabular}{|ll|}
\hline Variable & $\mathbf{N}=\mathbf{7 7}$ \\
\hline Sex & 38 \\
Male & 39 \\
\hline Female & \\
\hline Urban of residence & 49 \\
Rural & 28 \\
\hline Category of respondents & \\
\hline Policy makers/Program managers & 25 \\
Health workers & 18 \\
Parents of adolescents & 8 \\
Community leaders & 20 \\
Religious leaders & 6 \\
\hline Level of operation & \\
\hline LGA/Community & 52 \\
State & 25 \\
\hline
\end{tabular}

Table 3 shows the distribution of FGD respondents. In each of the community, one focus group discussion (FGD) was held with village heads. Furthermore, an FGD with adolescent boys and another with girls were held in each of the study communities 
Table 3

Socio-demographic distribution of FGD respondents

\begin{tabular}{|lc|}
\hline FGD participants & \\
\hline Number of FGD per community with village heads \\
\hline Variable $(\mathrm{N}=6)$ & 6 \\
\hline Sex & 0 \\
\hline Male & \\
Female & 3 \\
\hline Location & 3 \\
\hline Urban & \\
Rural & \\
\hline Number of FGD per community with adolescents \\
Variable (N=12) \\
\hline Location \\
\hline Rural \\
\hline Urban \\
\hline Sex \\
\hline Females \\
\hline Males
\end{tabular}

\section{Findings from the quantitative survey of adolescents}

Table 4 shows the current sources of SRH information to adolescents. It shows that out of 1045 adolescents that were surveyed, $635(60.5 \%)$ mentioned teachers as the commonest source of information on signs of puberty, followed by mothers, 418 (39.8\%). With respect to sources of information on relationship with opposite sex during puberty, majority of the adolescents reported that teachers were their main source 382(36.3\%), followed by their friends, $313(29.8 \%)$, and their mothers $252(24.0 \%)$. A considerable proportion of adolescents (27.9\%), stated that they had not received any information or advice on relationship with opposite sex at the time of the survey. 
Table 4

Sources of sexual and reproductive health information

\begin{tabular}{|lll|}
\hline Variables & Frequency & Percent \\
\hline ' Source of information on signs of puberty & & \\
\hline$\neg$ Teacher & 635 & 60.5 \\
\hline$\neg$ Mother & 418 & 39.8 \\
\hline$\neg$ Sibling & 197 & 18.6 \\
\hline$\neg$ No one & 192 & 18.6 \\
\hline$\neg$ Friends & 147 & 13.8 \\
\hline$\neg$ Father & 78 & 7.4 \\
\hline$\neg$ Guardian & 37 & 3.5 \\
\hline$\neg * *$ Other family member & 96 & 9.2 \\
\hline$\neg *$ Other & 62 & 6.0 \\
\hline+ Source of information on relationship with opposite sex & & \\
\hline$\neg$ Mother & 252 & 24.0 \\
\hline$\neg$ Father & 68 & 6.4 \\
\hline$\neg$ Guardian & 25 & 2.3 \\
\hline$\neg$ Sibling & 135 & 12.8 \\
\hline$\neg * *$ Other family member & 71 & 6.8 \\
\hline$\neg$ Teacher & 382 & 36.3 \\
\hline$\neg$ Friends & 313 & 29.8 \\
\hline$\neg$ No one & 70 & 27.9 \\
\hline$\neg *$ Other & & 6.7 \\
\hline+ Multiple response; *Internet, health workers, health product promoters & \\
\hline & & \\
\hline
\end{tabular}

Table 5 shows the relationship between adolescents' socio-demographic characteristics and their sources of information about puberty are shown in Table 2. Significant association was observed between age category and sources of information about puberty (other family members, teachers and friends) among adolescents ( $p \leq 0.003)$; place of residence and sources of information about puberty (parents/guardians and friends) ( $p \leq 0.03)$; Significant association was also found between gender and parents/guardians $(p<0.001)$, and other family members $(p<0.001)$, as well as between schooling status and teachers $(p=$ $0.001)$. 
Table 5

Socio-demographic correlates of sources of information about puberty

\begin{tabular}{|c|c|c|c|c|c|}
\hline \multirow[t]{2}{*}{ Variables } & $\mathbf{N}$ & $\begin{array}{l}\text { Parents/guardians } \\
f(\%)\end{array}$ & $\begin{array}{l}\text { Other family } \\
\text { members }\end{array}$ & $\begin{array}{l}\text { Teachers } \\
\mathrm{f}(\%)\end{array}$ & Friends $\mathrm{f}(\%)$ \\
\hline & & & $f(\%)$ & & \\
\hline
\end{tabular}

\section{Age category}

\begin{tabular}{llllll}
$13-15$ & 561 & $241(42.7)$ & $120(21.1)$ & $317(56.3)$ & $54(9.4)$ \\
\hline $16-18$ & 484 & $219(45)$ & $149(30.7)$ & $318(65.3)$ & $93(19)$ \\
\hline$\square^{2}(p-v a l u e)$ & & $0.51(0.48)$ & $12.55(<0.001)^{*}$ & 8.81 & $20.41(<$ \\
& & & & $(0.003)^{\star}$ & $0.001)^{\star}$
\end{tabular}

\section{Place of residence}

$\begin{array}{llllll}\text { Urban } & 551 & 285(51.9) & 156(28.1) & 352(63.6) & 90(16.1) \\ \text { Rural } & 494 & 175(35.4) & 113(22.9) & 283(57.3) & 57(11.5) \\ \square^{2}(p-\text { value }) & & 28.58(<0.001) * & 3.73(0.05) & 4.38(0.04) & 4.50(0.03)^{\star}\end{array}$

\section{Gender}

\begin{tabular}{llllll} 
Female & 598 & $344(67.3)$ & $188(31.2)$ & $373(62)$ & $85(14)$ \\
\hline Male & 447 & $116(25.8)$ & $81(17.9)$ & $262(58.4)$ & $62(13.6)$ \\
$\square^{2}(p$-value $)$ & & $102.6(<0.001)^{*}$ & $23.96(<0.001)^{\star}$ & $1.38(0.24)$ & $0.03(0.87)$
\end{tabular}

\section{Schooling status}

\begin{tabular}{llllll} 
In-school & 966 & $424(43.7)$ & $244(25)$ & $601(62)$ & $133(13.5)$ \\
\hline Out-of-school & 79 & $36(44.9)$ & $25(31.8)$ & $34(42.6)$ & $14(17.5)$ \\
\hline$\square^{2}$ (p-value) & & $0.04(0.84)$ & $1.77(0.18)$ & 11.45 & $0.99(0.32)$
\end{tabular}

* Statistically significant

Table 6 shows the relationship between adolescents' socio-demographic characteristics and their sources of information about puberty are shown in Table 3. Significant associations were found between age category, gender and sources of information about relationship with opposite sex (parents/guardians, other family members and friends) ( $p \leq 0.02)$; place of residence and sources of information about relationship with opposite sex (parents/guardians, other family members and teachers) $(p \leq 0.03)$. Schooling status was significantly associated with teachers. 
Table 6

Socio-demographic correlates of sources of information about relationships with opposite sex

\begin{tabular}{|c|c|c|c|c|c|}
\hline Variables & $\mathbf{N}$ & $\begin{array}{l}\text { Parents/guardians } \\
\mathrm{f}(\%)\end{array}$ & $\begin{array}{l}\text { Other family } \\
\text { Members } \\
\text { f(\%) }\end{array}$ & $\begin{array}{l}\text { Teachers } \\
\text { f(\%) }\end{array}$ & $\begin{array}{l}\text { Friends } \\
f(\%)\end{array}$ \\
\hline \multicolumn{6}{|l|}{ Age category } \\
\hline $13-15$ & 561 & $138(24.3)$ & $92(16.2)$ & $192(33.9)$ & $143(25.4)$ \\
\hline $16-18$ & 484 & $152(31.3)$ & 105 (21.6) & $190(39)$ & $170(34.8)$ \\
\hline$\square^{2}(p$-value $)$ & & $6.43(0.01)^{\star}$ & $5.01(0.02)^{\star}$ & $\begin{array}{l}2.85 \\
(0.09)\end{array}$ & $\begin{array}{l}10.93 \\
(0.001)^{*}\end{array}$ \\
\hline \multicolumn{6}{|l|}{$\begin{array}{l}\text { Place of } \\
\text { residence }\end{array}$} \\
\hline Urban & 551 & $179(32.5)$ & 118 (21.3) & $223(40.2)$ & 178 (32.2) \\
\hline Rural & 494 & $111(22.5)$ & $79(16)$ & 159 (32.2) & 135 (27.3) \\
\hline$a^{2}$ (p-value) & & $13.10(<0.001)^{\star}$ & $4.88(0.03)^{\star}$ & $\begin{array}{l}7.23 \\
(0.01)^{*}\end{array}$ & $2.93(0.09)$ \\
\hline \multicolumn{6}{|l|}{ Gender } \\
\hline Female & 598 & 202 (33.6) & $145(24.2)$ & $213(35.4)$ & $160(26.6)$ \\
\hline Male & 447 & $88(19.5)$ & $52(11.4)$ & $169(37.4)$ & $153(34.1)$ \\
\hline$q^{2}$ (p-value) & & $25.22(<0.001)^{*}$ & $27.56(<0.001)^{\star}$ & $\begin{array}{l}0.44 \\
(0.50)\end{array}$ & $6.97(0.01)$ * \\
\hline \multicolumn{6}{|l|}{$\begin{array}{l}\text { Schooling } \\
\text { status }\end{array}$} \\
\hline In-school & 966 & $264(27.1)$ & $180(18.4)$ & 363 (37.3) & $286(29.5)$ \\
\hline Out-of-school & 79 & $26(33)$ & $17(21.9)$ & $19(23.8)$ & $27(33.4)$ \\
\hline$\square^{2}$ (p-value) & & $1.24(0.26)$ & $0.56(0.45)$ & $\begin{array}{l}5.72 \\
(0.02) *\end{array}$ & $0.55(0.46)$ \\
\hline
\end{tabular}

\section{Findings from in-depth interviews and FGDs}

Participants highlighted that adolescents receive SRH information from various sources namely, teachers, peers/friends, family members and trusted adults, health workers, mainstream and social media, internet, and the church.

\section{Teachers}


They were frequently mentioned as a source of SRH information for adolescents, particularly for those who had attended or were attending school. They were said to provide information on topics such as puberty, sexuality transmitted diseases and relationship with the opposite sex. Some of the participants expressed their opinions thus,

"'Well as much as I know those in school get their sexual information from those teachers I talked about," (Male, Policy maker).

"Some school have added it in their curriculum that sexual education should be part of the studies in the schools, ... like myself, I teach them sex education, prevention of diseases like STDs" (HIZ01). (Health worker, Female)

\section{Friends/Peers}

Friends and peers were also frequently mentioned as a source of SRH information, particularly for out-ofschool adolescents but also as well for those in school. Adolescents were perceived to rely on one another and on their boy/girl friends for SRH information

"Majority of them get their information from their peer groups, including their boyfriends or girlfriends" (Policy maker, Male)

"We get the information through friends. For example, in my school if you don't have boyfriend, they will tell you that you have not started" (Adolescent, Female)

"Most adolescents receive information from their friends, in-school adolescents receive information from their classmates" (Policy maker, Female)

\section{Parents and family members}

Varied opinions were expressed by respondents about parents and family members being a source of $\mathrm{SRH}$ information for adolescents. It was noted that parents are a source of SRH information for adolescents who can confide in them. Trusted adults were also identified as a source of SRH information for adolescents

"Some adolescents get sexual and reproductive information from their mothers, for those who can confide in their mothers" (Policy maker, Male)

"Those [adolescents] out of school get SRH information from their trusted adult friends" (Policy maker, Male)

One participant categorically stated that family is the number one source of SRH information for a child, particularly information related to puberty and development of the reproductive system. 
"... Family is the number one, please. A child born into a family will definitely pass through the tutelage of the mother, the father and other immediate family who will definitely give such child information expected of him and especially the one relating to his growth into adolescent stage, the sexual reproductive health system" (School Principal, Male)

Contrary views were expressed by some respondents who lamented the fact that some parents do not provide SRH information to their children due to lack of awareness or knowledge, poor communication between parents and their children, and cultural inhibitions.

"Although most of the parents teach them (adolescents) other basic things, they do not educate their children on sex-related things" (School Principal, Female)

"Some parents are not even aware of the state of their child's health. Some of the adolescents do not even open up to their parents" (School Principal, Male)

\section{Health workers}

Although reported as an unpopular source, health workers were identified as a source of SRH information for some adolescents. It was stated that some adolescents preferred to visit informal health service providers such as patent medicine vendors (PMVs) for SRH information, rather than formal health service providers in the primary health centers. Typical responses were

"... Others get from the hospital, for those who visit the hospital" (Policy maker, Male)

"What they do is if they have problems that are related to that (SRH), they rather go to patent medicine dealers that will protect them so to speak..."(source?)(Policy maker, Male)

"... because of their tender age some of them are very shy to approach people [in the health center] to advise them or tell them this is what they should do or this is what they should not do" (source?) (Health worker, Female)

\section{Internet, mainstream and social media}

Internet and social media recurred among respondents as sources of $\mathrm{SRH}$ information for adolescents. Frequently mentioned social media sources were WhatsApp and Facebook which were described as providing information on what adolescents can do with respect to sexual relationships. Other mass media such as television and radio were also mentioned as sources of SRH information for adolescents

"In this era of explosive social media, most of them (adolescents) get information from social media; others get from television, radio"(Policy maker, Male)

"... So many discussions in WhatsApp and Facebook give people the insight of what adolescents can do and their sexual relationship" (Health worker, Female) 
"...internet determines the fate of our younger ones these days. They always browse and do so many things there" (Health worker, Male)

"We also get (SRH) information through television and radio ..."(Adolescent, Female)

\section{Church}

Some respondents mentioned the church as a source of $\mathrm{SRH}$ information, highlighting that the main focus of the church for adolescent SRH is abstinence from sex. One participant also correctly noted that some churches consider SRH as a topic which is not to be discussed with adolescents at all.

"In addition to other sources, they also get information from the church"(Parent, Male)

"...they can get from the church especially when the church has a programme. Two weeks ago, we had a programme here and we had to explain certain things to them (Religious Leader)

"...it depends, for some churches, during youth week, some churches invite some people to come and talk to them on that aspect (SRH) but for some other churches, it's a no go area" [laughs]. (Policy maker, Male)

\section{Preferred sources of SRH information and value placed on them by adolescents}

Adolescents repeatedly described friends, peers and social media as their most preferred sources of SRH information. A reason given for preferring their friends is that they feel comfortable and at ease to express their opinions to their friends. Conversing with friends about SRH was considered more interesting because there are no restrictions to topics discussed. Some adolescents also expressed that they trust their friends and can rely on them to keep discussions confidential. Some of their views are expressed in the following quotes:

"I prefer my friend because she will tell me her opinion, and I will tell her mine. When you are discussing with your friend and he/she is telling about those things [sex related matters], you can also tell him or her what you know about it and sometimes he/she will not know about an issue and, you will feel free to put her through."(Adolescent, Female)

"...friends are preferable, because speaking with friends is very interesting" (Adolescent, Male)

"...friends will tell us how to enjoy the real life unlike parents who will tell you that sex is not good" (Adolescent, Male)

In addition to the adolescents, many other respondents iterated that peers and friends are valued by adolescents, over other sources, as an important source of SRH information. This is because they trust their friends and can confide in them with very sensitive information. Friends were considered to be the first contact adolescents make for SRH information when a need arises because of a failure by parents and the school system to provide comprehensive information to adolescents. Overall, peers were considered a very strong influence and valued source of SRH information for adolescents. 
"There is no other place that they get this (SRH) information that will be more powerful than peer group" (Policy maker, Female)

"So for the reason that parents and teachers fail to teach them (adolescents) - and even when teachers are pushed by the adolescents, they don't open up to them - the only chance left for the adolescent is their peers" (Policy maker, Female)

".... we discovered that they (adolescents) have more confidence in their peers" (School principle female)

"Adolescents value that (SRH information) from peer groups because peer group will work on their brain to make sure they convince them"(School principle Male)

Concerning social media, adolescents preferred it because there are numerous platforms which are easy to join and from which they can connect with friends (make new friends from all over the world) and chat with them. Internet was also preferred because it is easy to access and there are no limits to information that can be sourced. In the words of an adolescent:

"Internet is more important because it is a network that contains all information and can be easily accessed. On Facebook you can use it to connect and chat with your friends all over the world" (Adolescent, Male)

A few adolescents mentioned parents and school teachers as a preferred source because they are most likely to provide the right information and direction for their adolescent.

"I prefer my parents because they provide the right information and they do not deceive their children. Most times, internet provides information that may provide opportunities to make wrong choice of information" (Adolescent, Male)

\section{Perceived adequacy and appropriateness of sources of SRH Information for adolescents}

Table 7 summarizes respondents' perceptions of adequacy and appropriateness of various sources of $\mathrm{SRH}$ information for adolescents which were previously mentioned. Parents, health workers and trained counselors were considered as adequate sources of SRH information for adolescents, whereas opinions were varied as to the adequacy and appropriateness of peers and social media as sources of SRH information.

Some respondents considered, information from primary health centers as adequate because there are trained health personnel as well as reading materials on SRH. They also reasoned that teachers could provide adequate $\mathrm{SRH}$ information if this becomes part of the school curriculum.

"Information from health centers (youth-friendly centers) is adequate, appropriate and tailored to the needs of the adolescents....that is why I talked about establishing adolescents' center" (Policy maker, Female) 
"In the health facility you can get that balanced information. Take for instance, if an adolescent is choosing any contraceptive method now, you give the person the pre-information on that particular method ... and at the end you counsel. So that makes it adequate" (Health worker, Female)

"Schools and parents maybe appropriate and adequate sources of information but social media and friends are not adequate and appropriate sources because they provide wrong information sometimes" (Health worker, Female)

Some participants attempted to compare various sources of information when considering the adequacy of SRH information provided. For instance, a community leader stated that health facilities are better positioned to provide SRH information, and on a more regular basis than schools.

"...What I am sure of is that the health facilities are trained institutions and are well organized for the provision of that kind of information (SRH information). In schools, trainings are done once in a while, not as regular as obtains in the health sector" (Community leader, Male)

One participant highlighted the value in combining various sources of information to achieve adequacy of SRH information to adolescents. Schools, churches and parents were considered by him as good but inadequate sources of information on their own. In his words,

"Schools, churches parents are good sources of information but independently the information they pass are inadequate, no source is enough in itself. A combination of sources may be adequate" (Policymaker, Male)

There was the tendency for some categories of respondents to consider themselves as an adequate source of SRH information for adolescents. For instance, parents more frequently identified parents as an adequate source of SRH information for adolescents, while health workers frequently mentioned themselves as an adequate source of information. 
Table 7

Respondents' perceptions of adequacy and appropriateness of sources of SRH information

\begin{tabular}{|lll|}
\hline Source of SRH information & Perceived adequacy & $\begin{array}{l}\text { Perceived } \\
\text { appropriateness }\end{array}$ \\
\hline Parents & $\begin{array}{l}\text { Adequate. } \\
\text { Usually targets the specific needs of } \\
\text { an adolescent }\end{array}$ & $\begin{array}{l}\text { Appropriate } \\
\text { Are in good position to } \\
\text { give correct } \\
\text { information }\end{array}$ \\
\hline $\begin{array}{l}\text { Health workers (primary health } \\
\text { centers and youth-friendly health } \\
\text { centers) }\end{array}$ & $\begin{array}{l}\text { Adequate. } \\
\text { Because information is balanced } \\
\text { and delivered by trained health } \\
\text { workers. } \\
\text { Also there is the availability of } \\
\text { training materials in health facilities }\end{array}$ & $\begin{array}{l}\text { Appropriate } \\
\text { They are well } \\
\text { informed on SRH }\end{array}$ \\
\hline issues
\end{tabular}

\section{Friends/peer group, social media, teachers and church are inadequate}

Most of the participants were of the view that information from friends/peer group, social media and the church are inadequate. A state level policymaker described information from boy/girlfriend, peers, chemists and social media to be deficient. Similarly, information gotten from school (teachers) and churches may be inadequate because these sources tend to mince words providing SRH information, hence don't give adequate and balanced information. According to some participants, the teachers and priests themselves may not have adequate information. For instance, SRH education may not be part of the school curriculum. Moreover, it was also observed by some of the participants that the church only focused on abstinence. One in her statement said that,

"Really what they get from their friends is not adequate...,You cannot give what you do not have. If their peers have the information they will give, but unfortunately they don't have it. (Policy maker, Female "The ones I assume not to be adequate are information they crave for on the internet and the videos, face book and so on and so forth. For example, when you talk about the video the actors and the actresses 
always act in the film hall not along the street but when these people are watching it they will assume that is being done along the street not knowing that they have a place where they do it". (Parent, Male I think the information they get from peer group is not adequate. Also, the ones they get from internet is not adequate because of varieties of views (Health worker, Female).

\section{Appropriateness of Sources of Information}

\section{Health facilities/youth friendly centers, parents and teachers are appropriate}

Most parents that took part in the study noted that the information from the parents are more appropriate than the ones they receive from the social media and peers. Youth friendly centers, and teachers in addition to parents were regarded as appropriate sources of SRH information by most state level policymakers and health workers. They believed that parents are in a good position to give correct information, while teachers and staff of youth friendly centers are well informed to guide the adolescents sexually.

"Schools and parents maybe appropriate and adequate sources of information but social media and friends are not adequate and appropriate sources."(Health worker, Male)

The health workers and school teachers give appropriate information because they are trained and qualified. Moreover, they do not also seem to get appropriate information from the social media because they do not understand the basis of what they read, watch and hear. The important thing to do is to provide them with the right information so that they can distinguish between what is detrimental and beneficial.

\section{Friends/Peer groups and social/mass media are inappropriate}

All participants were unanimous that Peer groups and social media are inappropriate as sources of SRH information to adolescent. Given as reason is that these sources can provide information that are distorted, based on misconception and could be misleading. They argued that their peers lack appropriate knowledge, but only provide information based on their individual experiences. They believed that the internet, for example, exposes adolescents to all manner of information, including, good and bad ones. Some of the quotes are:

"A girl with painful menstrual flow then she gets information from her peers that when she sleeps with a boy the menstrual pain will reduce. That type of information is it correct? No, but that is the information she has. Had it been her mother explained everything for her she will not listen to what her friends say. This kind of misinformation is based on past experiences which are misleading because of their wrong source of information" (School principal, Female)

"What they will get from the internet might be misleading because internet is a very broad place where you can get every information positive and negative and if the person is not guided, they are not that mature to be able to know the right or the wrong."(Religious leader, Male)

"In terms of appropriateness friends and peers are not because all they do is to share their personal experiences which can either be negative or positive in nature"(Village head. Male).

\section{Discussion}

The findings from this study show that teachers were the commonest source of SRH information, especially, to in-school adolescents on pubertal changes and relationship with the opposite sex. This is 
consistent with previous studies done in Nigeria [29] and other places, such as El Salvador, Central America,[30] Malawi North Africa [31]. So, adolescents, particularly the ones in school are most likely to learn about reproductive health first from school environment. In addition, schools have been reported as providing opportunities to learn about STIs, contraception, gender equality, and decision-making [30]. However, a study in Malaysia reported that friends were the most common source of SRH information [32]. This disparity in findings may be due to different study methods; while the study in Malaysia involved adolescents and other young adults, the current study was restricted to only adolescents.

Another common source of information to both in- and out-of-school adolescents identified in this study was friends/peers, and this is similar to results from researches in Pakistan [32] and Bangladesh [33]. This finding, further, justifies the claim that peer influence was the reason for a significant number of adolescents, in a study in Imo State, Southeast Nigeria, to engage in sexual activity [16]. Expectedly, concerns have been expressed regarding the quality of information from friends/peers, given their inexperience, but they could still become useful resource if well trained and supervised [32]. Other common sources of information to adolescents include mothers, and siblings, and these are not any different from results of some other studies that reported family as a common source of SRH information, although, amidst some difficulties, such as poor knowledge and feelings of embarrassment during sex-related discussions, as a result of cultural barriers [34-37]. Therefore, efforts to improve mothers' knowledge and confidence in discussing SRH may be beneficial to improving adolescents' SRH in view of the significant influence mothers have on their children's health-related attitudes and behaviours [38].

Social media was also, reported as a source of SRH information to adolescents in this study, and this is similar to the reports from other studies carried out in other parts Nigeria,[16, 39] and Zimbabwe [40]. Increasing availability and access to cell phones and other mobile technologies has made it possible to reach adolescents with SRH messages through the platform. This may be the reason the Centre for Disease Control and Prevention (CDC) highlighted the possibility to improve SRH of adolescents through innovative interventions using modern media technologies [41]. Further, adolescents mentioned books/novels, health education campaign in school, markets, and other community gatherings as sources of information. In another part of the country, a study observed that these sources were effective in transmitting information on STIs to adolescents [42].

Gender, age category, place of residence and schooling status were found to affect adolescents' sources of SRH information in our study. There were significant associations between sources of information about puberty (parents/guardians and other family members) and gender $(p<0.001)$. This is comparable to the observation from a study in Indonesia, where girls were more likely to discuss female pubertal changes with their mothers because they believed that their mothers had knowledge about such issues based on experience [43]. Also, age category had statistically significant associations with sources of information about relationships, such as, parents/guardians, other family members and friends, $(\mathrm{p} \leq$ 0.09). Correspondingly, it was documented in a study that while, adolescents, 15-18 years old relied mostly on peer groups and digital spaces for information about sex and relationships, younger 
adolescents, 10-14 years old relied less on the digital world [44]. Thus, it is imperative that ageappropriate interventions should be exploited in efforts to address adolescents' need for SRH information.

As reported in previous studies, $[22,45,46]$ the current study found that adolescents would prefer, in decreasing order of importance, friends, social and mass media, and parents as their sources of SRH information. They feel free to discuss and share any information with their friends, and in the process, learn how to avoid negative results associated with sexual activities $[47,48]$. The popularity of friends and the internet among adolescents were reinforced by the position of the different stakeholders on the relative values of the various information platforms to adolescents in this study. In their separate discussions they held the opinion that internets and friends were of greater value to adolescents than other sources. Hence, the need to explore peer education as adolescents often view their friends or peer as safe and reliable confidents [49]. On the other hand, information from the media can have beneficial or detrimental effects on the adolescents depending on the content and how censored they are. Thus, intervention programmes targeting the media as a platform to disseminate SRH information to adolescents should incorporate measures to prevent media misuse by adolescents. Conversely, some studies in the past reported parents as mostly preferred by adolescents $[18,50]$. This may be a reflection of the declining relevance of the African family culture and the increasing influence of peers in the development of the young person [51]. Also, a study carried out in Vanuatu reported adolescents' preferred sources as peer educators and health workers, but parents were preferred by female adolescents [52].

All the stakeholders in our study thought that parents/families are adequate sources of SRH information to adolescents. This is consistent with the findings from previous studies conducted in Ghana and Egypt, where mothers were reported to have sufficiently provided SRH information to their adolescents $[53,54]$. However, this differs from the results from a study in El Salvador which reported that adolescents were not getting enough information from parents [30]. Likewise, most stakeholders in the current study believed that health workers and teachers also provide adequate SRH information to adolescents. This contradicts the result from a study in South Africa, where nurses complained that the time allocated to them during clinics was not enough to provide sufficient SRH information to adolescents [55]. This difference in findings is probably because the study in South Africa involved only health workers unlike the present study involved other adolescent sexual and reproductive health (ASRH) stakeholders.

There was unanimity among the stakeholders that peers and social media were inadequate. This affirms the view expressed in a previous study that adolescents lack basic knowledge of human reproductive biology and infection prevention methods because they tend to rely on their peers and social media for such information [56]. Also, churches and schools were considered inadequate in SRH provision to adolescents. While churches are known to focus only on chastity, the delivery of SRH information in secondary schools were insufficient and not standardized [18] 
Health facilities, parents, teachers and youth friendly centers were considered appropriate sources of SRH information to adolescents by most of the participants. This finding is in line with those from other studies in the past which reported that these sources were appropriate for dissemination of SRH information to adolescents $[57,58]$. On the contrary, peers and social media were viewed as inappropriate as previously reported in a study in Delhi where participants felt that information from friends were wrong while those from the media encouraged them to indulge in unhealthy sexual behaviours [59]. Similarly, another study reported that the media (radio, newspaper, internet, etc) never informed adolescents about their SRH, but only increased their interest in pornography, and promoted risky sexual behaviors [30].

A study is without limitations and ours is not an exception. Thus, the findings from this study should be interpreted within its limitations, such as the sensitive nature of the study. Our people treat sexual issues with utmost secrecy and privacy, and hence, may not be inclined to freely discuss them or divulge information accurately. This may have affected the responses given by some of the participants, and possibly leading to information bias. However, we tried to minimize this by using gender-sensitive interview guides, ensuring confidentiality and, having the interviews and discussions in safe environments where participants could express themselves freely. We also used mixed methods of data collection and elicited information from other stakeholders apart from adolescents, thereby obtaining a more comprehensive representation on adolescents' sources of SRH information for effective interventions.

\section{Conclusion}

Adolescents receive SRH information from a variety of sources, but they prefer sources that guarantee confidentiality and ease of access, even if these sources are considered inappropriate by their parents and other stakeholders. Adolescents value sources that guarantee confidentiality, trust and ease of access. This may inform their preference for certain sources of SRH, which may not always be the best in terms of content, quality and accuracy.

Interventions for addressing the need of adolescents for SRH information should be targeted at their valued and preferred sources, whilst maintaining a delicate balance with the choices and expectations of their parents and adult family members. Hence, there is need to design and implement specific interventions linked to online platforms as well as to parents and policy makers. Peer education programmes should be designed and implemented in order to provide the right SRH information among their peers. Likewise, there is need for the inclusion of comprehensive SRH education into secondary school curricular.

\section{Abbreviations}

ASRH:

Adolescent Sexual and Reproductive Health 
FGD:

Focus group discussions

IDI:

In-depth Interview

IDRC:

International Development Research Centre

SRH:

Sexual and Reproductive Health

SRHR:

Sexual and Reproductive Health Rights

STI:

Sexually transmitted infection

ICPD:

International Conference on Population and Development

\section{Declarations}

\section{Ethics approval and consent to participate}

The project protocol was submitted to the Health Research Ethics Committee of University of Nigeria Teaching Hospital Enugu and the Research and Ethics Committee of Ebonyi State Ministry of Health. Ethical approval was secured from both committees before entry into the study site. Informed written consent was obtained from study participants prior to each interview. A written consent was also obtained from FGD discussants (adolescents, village heads). Prior to survey data collection, written informed consent was obtained from parents/guardians of adolescents aged 13 to 17 years whereas adolescents aged 18 years gave consent for themselves.

Consent for publication

Not applicable

Availability of data and materials 
The dataset used for this study is available and can be obtained from the corresponding author upon request.

\section{Competing interests}

The authors declare that there is no competing interest

\section{Funding}

The research project which led to the results included in this manuscript received funding from IDRC MENA+WA implementation research project on maternal and child health (IDRC grant number: 108677). The funders did not participate in designing the study, collecting and analyzing data, or writing and reviewing the manuscript. The views expressed in this manuscript belong exclusively to the authors and do not necessarily represent the funders' opinions.

\section{Author information:}

\section{Contributions}

$\mathrm{CM}, \mathrm{NE}, \mathrm{OO}$ conceptualized and designed the study and data collection instruments. $\mathrm{CA}, \mathrm{CM}, \mathrm{IA}, \mathrm{CO}, \mathrm{UE}$, carried out data collection. All authors took part in data analysis. CA wrote the first draft of the manuscript, while all the authors read, revised and approved the final version for submission.

\section{Acknowledgements}

We thank all the study participants for their willingness to take part in the study.

\section{Authors qualifications:}

Chibuike Agu - MBBS, MPH; Chinyere Mbachu - MBBS, MPH; Ifunanya Agu - BSc, MSc- Health promotion and communication; Chinyere Okeke - MBBS, MPH; Uchenna Ezenwaka - BSc, MPH; Mildred Ndubuisi MBBS; Nkoli Ezumah - PhD-Sociology; Obinna Onwujekwe- MBBS, PhD-Health economics.

\section{References}

1. Adolescent Demographics - UNICEF Data [Internet]. [cited 2019 Oct 17]. Available from: https://data.unicef.org/topic/adolescents/demographics/

2. Adolescent And Youth Demographics: A Brief Overview [Internet]. [cited 2020 Apr 17]. Available from: https://www.unfpa.org/sites/default/files/resource-pdf/One pager on youth demographics

3. Ayalew M, Mengistie B, Semahegn A. Adolescent - Parent communication on sexual and reproductive health issues among high school students in Dire Dawa, Eastern Ethiopia: A cross sectional study. Reprod Health. 2014;11.

4. Papathanasiou I, Lahana E. : Adolescence, Sexuality and Sexual Education. Heal Sci J. 2006;1. 
5. Halpern CT, Udry JR, Campbell B, Suchindran C. Testosterone and pubertal development as predictors of sexual activity: A panel analysis of adolescent males. Psychosom Med. 1993;55:43647.

6. The Facts Adolescent Reproductive Health in Nigeria [Internet]. [cited 2019 Oct 17]. Available from: www.advocatesforyouth.org

7. Eze UO. Prevention of sexual assault in Nigeria. Ann Ibadan Postgrad Med. 2013;11:65-70.

8. Ngwenya S. Communication of reproductive health information to the rural girl child in Filabusi, Zimbabwe. Afr Health Sci. 2016;16:451-61.

9. Ngilangwa DP, Rajesh S, Kawala M, Mbeba R, Sambili B, Mkuwa S, et al. Accessibility to sexual and reproductive health and rights education among marginalized youth in selected districts of Tanzania. Pan Afr Med J. 2016;25:2.

10. UN Population Fund (UNFPA) Report of the International Conference on Population and Development [Internet]. [cited 2019 Oct 17]. Available from https://www.un.org

11. Omo-aghoja L., Omo-aghoja V., Aghoja C., Okonofua F., Aghedo O, Umueri C, et al. Factors associated with the knowledge, practice and perceptions of contraception in rural southern Nigeria. Ghana Med J. 2010;43.

12. Unaids. UNAIDS report on the global AIDS epidemic 2013 GLOBAL REPORT. 2013.

13. Okonofua F. New Research Findings on Adolescent Reproductive Health in Africa. Afr J Reprod Health. 2007;11:7-9.

14. Görgen R, Yansane ML, Marx M MD. Sexual Behavior and Attitudes Among Unmarried Urban Youths in Guinea. Int Fam Plan Perspect. 1998;24:65-71.

15. National Coalition for Sexual Health. The sexual health of youth in the United States sexual health, an audience profile 2013. Available from: https://nationalcoalitionforsexualhealth.org/dataresearch/audience-profiles/document/

16. Envuladu EA. Exploring The influencing factors on adolescent sexual behaviour and reproductive health challenges in Nigeria: A case study of Plateau State. [Internet]. [cited 2020 Apr 17]. Available from: https://bibalex.org/baifa/Attachment/Documents/

17. Mbachu CO, Agu IC, Eze I, Agu C, Ezenwaka U, Ezumah N, et al. Exploring issues in caregivers and parent communication of sexual and reproductive health matters with adolescents in Ebonyi state, Nigeria. BMC Public Health. 2020;20:77.

18. Muhwezi WW, Katahoire AR, Banura C, Mugooda H, Kwesiga D, Bastien S, et al. Perceptions and experiences of adolescents, parents and school administrators regarding adolescent-parent communication on sexual and reproductive health issues in urban and rural Uganda. Reprod Health. 2015;12:110.

19. Sani AS, Abraham C, Denford S, Mathews C. Design, implementation and evaluation of school-based sexual health education in sub-Saharan Africa: a qualitative study of researchers' perspectives. Sex Educ. 2018;18:172-90. 
20. Esiet AO. Adolescent Sexual and Reproductive Health in Nigeria Action Health Incorporated Promoting Youth Health and Development. [Internet]. [cited 2020 Jun 17]. available from: https://www.wilsoncenter.org/sites/default/files/media/documents/event/

21. Ybarra ML, Emenyonu N, Nansera D, Kiwanuka J, Bangsberg DR. Health information seeking among Mbararan adolescents: Results from the Uganda Media and You survey. Health Educ Res. 2008;23:249-58.

22. Baheiraei A, Khoori E, Foroushani AR, Ahmadi F, Ybarra ML. What sources do adolescents turn to for information about their health concerns? Int J Adolesc Med Health. 2014;26:61-8.

23. National Population Commission (NPC) [Nigeria] and ICF 2019. Nigeria Demographic and Health Survey 2018. Abuja, Nigeria, and Rockville, Maryland, USA: NPC and ICF

24. Nwagha UI, Nwachukwu D, Dim C, Ibekwe PC, Onyebuchi A. Maternal mortality trend in South East Nigeria: less than a decade to the millennium developmental goals. J Womens Health (Larchmt). 2010;19:323-7.

25. Ebonyi State Strategic Health Development Plan 2010-2015.doc - Google Drive [Internet]. [cited 2020 Apr 15]. Available from: https://drive.google.com/file/d/0B1DAmtM1BcbMWU1QTF9USjJTZFU/view

26. Chigozie Jesse Uneke A, Chinwendu Daniel Ndukwe MBBS M, Abel Abeh Ezeoha Henry Urochukwu MBBS F. This evidence-based policy brief includes:-A description of a health system problem-Viable options for addressing this problem-Strategies for implementing these options What is an evidencebased policy brief? What is a systematic review? 2013.

27. Israel, G.D. (1992) Sampling The Evidence of Extension Program Impact. Program Evaluation and Organizational Development, IFAS, University of Florida; PEOD-5. - References - Scientific Research Publishing [Internet]. [cited 2020 Feb 8]. Available from: https://www.scirp.org/(S(oyulxb452alnt1aej1nfow45))/reference/ReferencesPapers.aspx? ReferencelD=1637875

28. Cleland J. Illustrative Questionnaire for interview-Surveys with Young People. Asking young people about sexual and reproductive behaviours: Illustrative Core Instruments, Geneva: World Health Organization. 2001.

29. Abiodun O, Olu Abiodun O. Sexual and Reproductive Health Knowledge and Service Utilization among In-school Rural Adolescents in Nigeria. J AIDS Clin Res. 2016;7:1-8.

30. Cortez R, Revuelta K-A, Guirola Y. Adolescent Sexual and Reproductive Health In El Salvador. Discussion paper June, 2015.

31. Munthali AC, Mbendela M, Mezuwa H, Banda T. Final evaluation of the joint programme on adolescent girls in Malawi. [Internet]. [cited 2020 Jun 17]. available from: https://svri.org

32. Shaikh BT, Rahim ST. Assessing knowledge, exploring needs: A reproductive health survey of adolescents and young adults in Pakistan. Vol. 11, European Journal of Contraception and Reproductive Health Care. 2006. p. 132-7.

33. Bachera Aktar, Malabika Sarker, Andrew Jenkins. Exploring Adolescent Reproductive Health Knowledge, Perceptions, and Behavior, Among Students of Non-Government Secondary Schools 
Supported by BRAC Mentoring Program in Rural Bangladesh. J Asian Midwives. 2014;1:17-33.

34. Bankole A, Biddlecom A, Guiella G, Singh S, Zulu E. Sexual behavior, knowledge and information sources of very young adolescents in four sub-Saharan African countries. Afr J Reprod Health. 2007;11:28-43.

35. Boyar R, Levine D ZN. Techsex USA Youth Sexuality and Reproductive Health in the Digital Age. Oakland, CA:; 2011.

36. Nonoyama M, Tsurugi Y, Shirai C, Ishikawa Y, Horiguchi M. Influences of sex-related information for STD prevention. J Adolesc Heal. 2005;36:442-5.

37. Shams M, Parhizkar S, Mousavizadeh A, Majdpour M. Mothers' views about sexual health education for their adolescent daughters: A qualitative study. Reprod Health. 2017;14:24.

38. Bastien S, Kajula L, Muhwezi W. A review of studies of parent-child communication about sexuality and HIV/AIDS in sub-Saharan Africa. Vol. 8, Reproductive Health. 2011.

39. Francis EA, Chizoba GV, Adesola O. Using Mobile Technology to Access Sexual and Reproductive Health Information and Services by Adolescent \& Young Persons: Findings from Nigeria. Univers J Public Heal. 2019;7:73-81.

40. Ndlovu RJ, Sihlangu RH. Preferred sources of information on AIDS among high school students from selected schools in Zimbabwe. J Adv Nurs. 1992;17:507-13.

41. CDC, Kachur, Mesnick, Liddon, Kapsimalis, Habel, et al. Adolescents, Technology and Reducing Risk for HIV, STDs and Pregnancy. [Internet]. [cited 2020 Jun 17]. Available from: https://www.cdc.gov/std/life-stages-populations/Adolescents-white-paper.pdf

42. Temin MJ, Okonofua FE, Omorodion FO, Renne EP, Coplan P, Kris Heggenhougen $\mathrm{H}$, et al. Perceptions of Sexual Behavior and Knowledge About Sexually Transmitted Diseases Among Adolescents in Benin City, Nigeria. International Family Planning Perspectives 1999 p. 186-90.

43. Elly Nurachmaha, Yati Afiyant, Sri Yona, Rita Ismail, John Toding Padang, Ketut Suardana, Yulia Irvan Dewit KKD. Mother-daugther communication about sexual and reproductive health issues in Singkawang, West Kalimantan, Indonesia. 2018;28:172-5.

44. Switched on: sexuality education in the digital space - UNESCO Digital Library [Internet]. [cited 2020 Jun 5]. Available from: https://unesdoc.unesco.org/ark:/48223/pf0000372784

45. Onukwugha Fl, Hayter M, Magadi MA. Views of service providers and adolescents on use of sexual and reproductive health services by adolescents: A systematic review. Afr J Reprod Health. 2019;23:134-47.

46. Iqbal S, Zakar R, Zakar MZ, Fischer F. Perceptions of adolescents' sexual and reproductive health and rights: A cross-sectional study in Lahore District, Pakistan. BMC Int Health Hum Rights. 2017;17:113.

47. Nobelius AM, Kalina B, Pool R, Whitworth J, Chesters J, Power R. Sexual and reproductive health information sources preferred by out-of-school adolescents in rural southwest Uganda. Sex Educ. 2010;10:91-107. 
48. Janet Chepkoech, Marie Khanyanji Khayesi JOO. Sources of Information on Reproductive Health among Teenage Girls in Kaptembwo, Nakuru County, Kenya [Internet]. [cited 2020 Feb 17]. Available from: http://article.sapub.org/10.5923.j.library.20190801.03.html

49. Adolescent sexual and reproductive health. The 2018 Inter-agency field manual on reproductive health in humanitarian setting. Available from: https://cms.emergency.unhcr.org/documents/

50. World Health Organization (WHO). Summaries of projects in developing countries assisting the parents of adolescents. 2007. Available from:

https://www.who.int/maternal_child_adolescent/documents/9789241595667/en/

51. Dehne KL, Riedner G. Sexually transmitted infections among adolescents: The need for adequate health services. Reprod Health Matters. 2001;9:170-83.

52. Kennedy EC, Bulu S, Harris J, Humphreys D, Malverus J, Gray NJ. "these issues aren't talked about at home": A qualitative study of the sexual and reproductive health information preferences of adolescents in Vanuatu. BMC Public Health. 2014;14.

53. Quaye SJ. Sexual and reproductive health iformation seeking behaviour among students: A study of Labone senior high school. 2013.

54. Mother-Daughter Communication About Sexual and Reproductive Health in Rural Areas of Alexandria, Egypt - Population Reference Bureau [Internet]. [cited 2020 Feb 18]. Available from: https://www.prb.org/egypt-mother-daughter-sexualhealth/

55. Jonas K, Crutzen R, Krumeich A, Roman N, van den Borne B, Reddy P. Healthcare workers' beliefs, motivations and behaviours affecting adequate provision of sexual and reproductive healthcare services to adolescents in Cape Town, South Africa: a qualitative study. BMC Health Serv Res. 2018;18:109.

56. Titiloye MA, Ajuwon AJ. Knowledge and quality of adolescents reproductive health communication between parents and their adolescents children in Ibadan, Nigeria. J Public Health Africa. 2017;8:103-10.

57. Tabong PT-N, Maya ET, Adda-Balinia T, Kusi-Appouh D, Birungi H, Tabsoba P, et al. Acceptability and stakeholders perspectives on feasibility of using trained psychologists and health workers to deliver school-based sexual and reproductive health services to adolescents in urban Accra, Ghana. Reprod Health. 2018;15:122.

58. Tilahun M, Mengistie B, Egata G, Reda AA. Health workers' attitudes toward sexual and reproductive health services for unmarried adolescents in Ethiopia. Reprod Health. 2012;9.

59. Meena JK, Verma A, Kishore J, Ingle GK. Sexual and Reproductive Health: Knowledge, Attitude, and Perceptions among Young Unmarried Male Residents of Delhi. Int J Reprod Med. 2015;2015:1-6.

\section{Supplementary Files}

This is a list of supplementary files associated with this preprint. Click to download. 
- Supplementaryfile4.docx

- Supplementaryfile3.docx

- Supplementaryfile2.docx

- Supplementaryfile1.pdf

- STROBEchecklistcrosssectional.doc 